\title{
The knock-down of overexpressed EZH2 and BMI-1 does not prevent osteosarcoma growth
}

\author{
HIROMI SASAKI", TAKAO SETOGUCHI*, YUKIHIRO MATSUNOSHITA, \\ HUI GAO, MASATAKA HIROTSU and SETSURO KOMIYA \\ ${ }^{1}$ Department of Orthopaedic Surgery, Graduate School of Medical and Dental Sciences,
Kagoshima University, 8-35-1 Sakuragaoka, Kagoshima 890-8520, Japan
}

Received September 17, 2009; Accepted October 12, 2009

DOI: $10.3892 /$ or_00000684

\begin{abstract}
Polycomb group proteins control the transcriptional memory of cells by maintaining the stable silencing of specific sets of genes through chromatin modifications. Polycomb group protein complexes control gene repression through recruitment of histone deacetylase. This recruitment leads to trimethylation of $\mathrm{Lys}_{27}$ of histone H3 (H3K27). Histone H3K27 trimethylation is a property of stably silenced heterochromatin. EZH2 and BMI-1 are pivotal components of polycomb group protein complexes. Increased $E Z H 2$ levels have been found in several malignancies and reported as a molecular biomarker of poor prognosis. Similarly, BMI-1 has also been found to be associated with malignant transformation. In addition, inhibition of EZH2 or BMI-1 inhibits the growth of various types of malignancies. The expression of $B M I-1$ and $E Z H 2$ in human osteosarcoma has not been clearly determined. We examined the potential involvement of aberrant polycomb group protein expression in the pathogenesis of osteosarcoma. Real-time PCR revealed that expression of EZH2 in 143B, HOS, NOS-1 and Saos2 was increased compared to normal osteoblasts. BMI-1 was also up-regulated in 143B, HOS and NOS-1. Expression of EZH2 and BMI- 1 were up-regulated in osteosarcoma patient biopsy specimens compared to normal bone. Immunohistochemical examinations showed that EZH2 and BMI-1 were up-regulated in osteosarcoma cells and that trimethylation of histone $\mathrm{H} 3 \mathrm{~K} 27$ was increased. We examined the effects of knock down of EZH2 and BMI- 1 by shRNA. Unexpectedly, the knock-down of EZH2 and BMI-I did not prevent osteosarcoma growth either in vitro or in vivo. Our findings suggest that EZH2 and BMI-1 may be tumor-
\end{abstract}

Correspondence to: Dr Takao Setoguchi, Department of Orthopaedic Surgery, Graduate School of Medical and Dental Sciences, Kagoshima University, 8-35-1 Sakuragaoka, Kagoshima 890-8520, Japan

E-mail: setoro@m2.kufm.kagoshima-u.ac.jp

*Contributed equally

Key words: polycomb protein, osteosarcoma, EZH2, BMI-1 associated antigens of osteosarcoma, but are not useful molecular targets of osteosarcoma treatment.

\section{Introduction}

Osteosarcoma is the most common primary bone cancer occurring mainly in children (1). Standard treatment involves the use of 'up-front' multi-agent chemotherapy, definitive surgery of the primary tumor and postoperative chemotherapy. In recent years, great effort has been made aiming at elucidating the molecular events underpinning the biology of osteosarcoma including dysregulation of cell division and apoptotic processes. Although such dysregulation may constitute a potent source of new therapeutic targets, the molecular mechanisms of regulation of osteosarcoma cell proliferation are largely unknown.

Polycomb group $(\mathrm{PcG})$ proteins control the transcriptional memory of cells by maintaining the stable silencing of specific sets of genes through chromatin modifications (2). Two distinct and evolutionarily conserved PcG complexes have been identified, consisting of various $\mathrm{PcG}$ proteins and non-PcG proteins. The polycomb repressive complex 1 (PRC1) contains the BMI-1, MEL-18, RING1, HPH and HPC PcG proteins, while the polycomb repressive complex 2 (PRC2) contains the EZH2, EED, YY1 and SUZ PcG proteins (3-15). EZH2 is a histone methyltransferase associated with transcriptional repression. EZH2 catalyzes trimethylation of histone $\mathrm{H} 3$ at lysine 27 (H3K27) (16-19).

Recent findings have linked deregulated expression of human PcG genes to malignant transformation, loss of differentiation in tumor cells, and metastatic behavior (20). Increased $E Z H 2$ levels have been found in several epithelial tumors (21-26) and in various hematological malignancies (27-29). Similarly, BMI- 1 has also been associated with malignant transformation $(23,27,30-38)$. The expression of $B M I-1$ and EZH2 in human osteosarcoma cell lines and osteosarcoma patient specimens have not been well defined. To explore the potential involvement of aberrant PcG expression in the pathogenesis of osteosarcoma, we investigated the expression of EZH2 and BMI-1 in osteosarcoma cell lines and patient samples. We next examined the status of trimethylation of H3K27. In addition, we examined the effect of the knock-down of EZH2 and BMI-I by shRNA in vitro and in vivo. 


\section{Materials and methods}

Cell culture. HOS, 143B and Saos2 cells were purchased from the American Type Culture Collection (ATCC). NOS-1 was purchased from RIKEN cell bank (39). Cells were grown in Dulbecco's modified Eagle's medium (DMEM) supplemented with $10 \% \mathrm{FBS}$, penicillin $(100 \mathrm{U} / \mathrm{ml})$ and streptomycin $(100 \mu \mathrm{g} / \mathrm{ml})$. Human osteoblast cells (NHOst) were purchased from Sanko Junyaku (Tokyo, Japan). Cells were cultured with $\mathrm{OBM}^{\mathrm{TM}}$ (Cambrex, NJ, USA) or DMEM supplemented with $10 \%$ FBS. All cells were grown in a humidified atmosphere containing $5 \% \mathrm{CO}_{2}$ at $37^{\circ} \mathrm{C}$.

Patient osteosarcoma biopsy specimens. All human osteosarcoma biopsy specimens were obtained from primary lesions. Biopsy was performed before chemotherapy or radio therapy to make the diagnosis.

$R T-P C R$. Each sample was run minimally at three concentrations in triplicate. All primer sets amplified 100- to 200-bp fragments. Total RNA was extracted using the miRVana RNA isolation system (Ambion, TX, USA) or TRIzol (Invitrogen, CA, USA). Reactions were run using SYBRGreen (Bio-Rad, CA, USA) on a MiniOpticon ${ }^{\mathrm{TM}}$ machine (Bio-Rad). The comparative $\mathrm{Ct}(\Delta \Delta \mathrm{Ct})$ method was used to determine fold change in expression using BII-microglobulin. Each sample was run minimally at three concentrations in triplicate. The following primers were used. EZH2: 5-TTCA TGCAACACCCAACACT-3, 5-GAGAGCAGCAGCAAAC TCCT-3; BMI-1: 5-TTCATTGATGCCACAACCAT-3, 5-GTA CTGGGGCTAGGCAAACA; ßII-microglobulin: 5-TCAATG TCGGATGGATGAAA-3, 5-GTGCTCGCGCTACTCTC TCT-3.

Cell proliferation assay. MTT assay: Cells were incubated with substrate with MTT [3-(4,5-dimethylthiazol-2-yl)-2,5diphenyltetrazolium bromide] for $4 \mathrm{~h}$ and washed with PBS and lysed to release formazan from cells. Then cells were analyzed in a Safire microplate reader (Bio-Rad) at $562 \mathrm{~nm}$. shRNAs were purchased from (SABiosciences, MD, USA). Lipofection of siRNA was performed every other day as recommended in the supplier's protocol using FuGENE 6 (Roche, Basel, Switzerland).

Immunohistochemistry. The following primary antibodies were used: anti-EZH2 (diluted 1:200 Zymed Laboratories, CA, USA), anti-BMI-1 (diluted 1:200 R\&D Systems, MN, USA), and anti-trimethylated H3K27 (diluted 1:200 Abcam, Cambridge, UK). The following secondary antibodies were used: fluorescein-conjugated goat anti-mouse $\mathrm{IgG}$ antibody (diluted 1:200; Jackson ImmunoResearch, PA, USA) and rhodamine-conjugated donkey anti-rabbit IgG antibody (diluted 1:200; Chemicon, CA, USA). The cells were counterstained with Hoechst 33258 to identify nuclei. Immunohistochemistry with each second antibody alone without primary antibody was performed as a control.

Animal experiments. shRNA-transfected 143B cells $\left(1 \times 10^{5}\right)$ were mixed with collagen gel in a 1:1 volume and inoculated subcutaneously in 5-week-old nude mice. Tumor size was measured, and tumor volume was calculated using the formula $\mathrm{LW}^{2} / 2$ (with $\mathrm{L}$ and $\mathrm{W}$ representing the length and width of tumors). All experimental procedures were performed in compliance with the guiding principles for the Care and Use of Animals described in the American Journal of Physiology and with the Guidelines established by the Institute of Laboratory Animal Sciences, Faculty of Medicine, Kagoshima University. All efforts were made to minimize animal suffering, to reduce the number of animals used and to utilize possible alternatives to in vivo techniques.

Data analysis. Each sample was analyzed in triplicate and experiments were repeated three times. In figures the error bar means standard error. Data were analyzed by the STASTISCA (StatSoft, OK, USA). Differences between mean values were evaluated by the unpaired t-test and differences in frequencies were evaluated by Fisher's exact test. Results were considered statistically significant at $\mathrm{P}<0.05$.

\section{Results}

Overexpression of EZH2 and BMI-1 in osteosarcoma. RT-PCR was performed to examine the expression of $E Z H 2$ and $B M I-1$ in osteosarcoma cell lines. RT-PCR revealed that NOS-1, HOS and 143B osteosarcoma cell lines expressed EZH2 more strongly than normal human osteoblasts (NHOst) (Fig. 1A). More sensitive real-time PCR analyses revealed that expression of EZH2 in 143B, HOS, NOS-1 and Saos2 was increased 13-, 11-, 4.9- and 4.4-fold, respectively (Fig. 1B). RT-PCR revealed that NOS-1, HOS and 143B osteosarcoma cell lines expressed BMI-1 more strongly than NHOst (Fig. 1C). Real-time PCR revealed that expression of BMI-1 in 143B, HOS and NOS-1 was increased 6.7-, 3.7- and 3.7-fold, respectively, while that in Saos2 did not change appreciably (Fig. 1D). We next examined the expression of EZH2 and BMI-1 in osteosarcoma patient biopsy samples. RT-PCR revealed that 3 osteosarcoma patient samples expressed EZH2 more strongly than normal bone tissue (Fig. 1E). Real-time PCR revealed that expression of $E Z H 2$ in patient samples was increased 1.4- to 4.2-fold (Fig. 1F). RT-PCR revealed that 3 osteosarcoma patient samples expressed BMI-1 more strongly than normal bone (Fig. 1G). Real-time PCR revealed that expression of BMI- 1 in patient samples increased 4.5- to 9.4fold (Fig. 1H). To extend these findings, we performed immunohistochemistry for EZH2 and BMI-1 examination revealed that osteosarcoma cell lines and osteosarcoma patient samples expressed EZH2 and BMI-1 more strongly than normal bone tissue (Fig. 2A and B). EZH2 and BMI-1 were localized in the nucleus of osteosarcoma cells (Fig. 2A and $\mathrm{B}$ ). These findings showed that EZH2 and BMI-1 are overexpressed in osteosarcomas.

Histone H3-K27 is trimethylated in osteosarcoma. To determine if overexpression of polycomb proteins promoted histone H3K27 trimethylation, we performed immunohistochemical examination using trimethylated histone H3K27-specific antibody. Histone H3K27 was found to be trimethylated more strongly in osteosarcoma cells lines and osteosarcoma patient samples than in normal osteoblasts and bone tissue (Fig. 2C). 

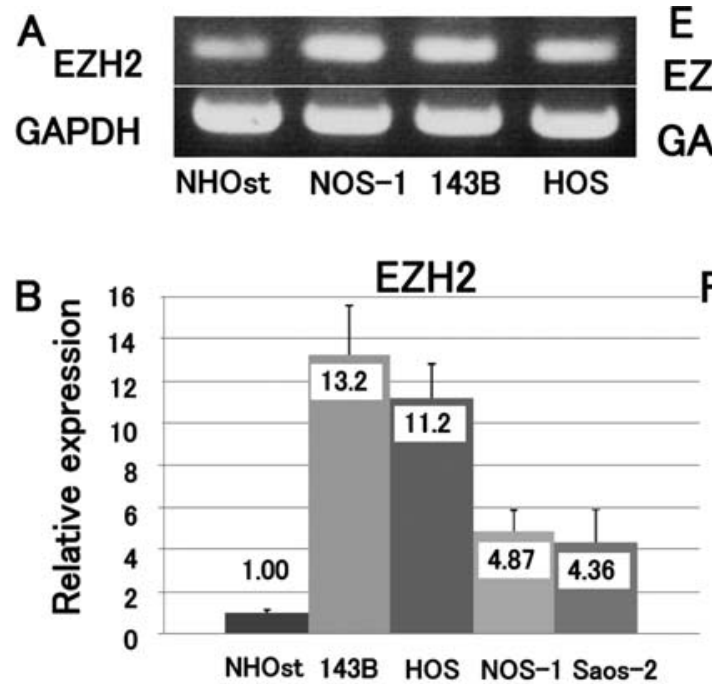

C

BMI-1

GAPDH

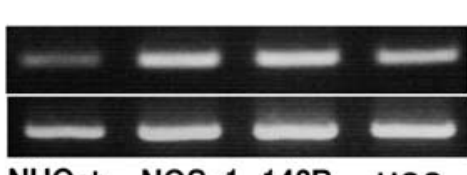

NHOst NOS-1 143B HOS

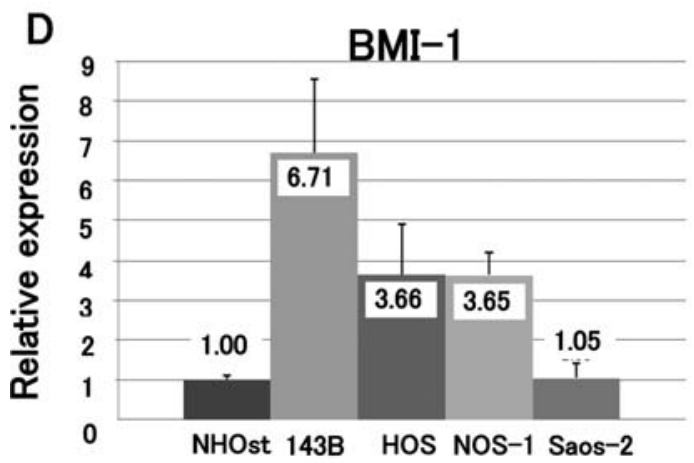

\section{E EZH2 GAPDH}

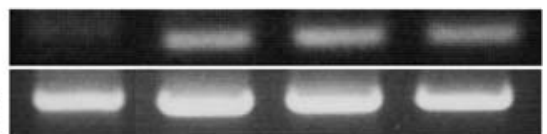

normal OS1 OS2 OS3 bone

$F$

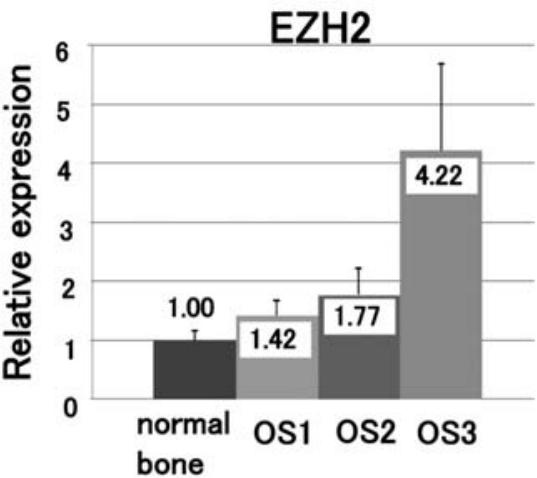

G bone

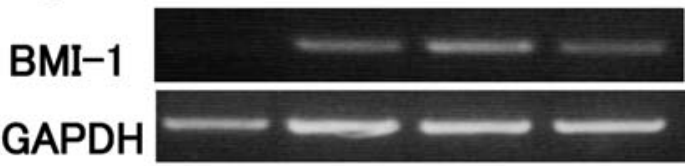

normal OS1 OS2 OS3

H
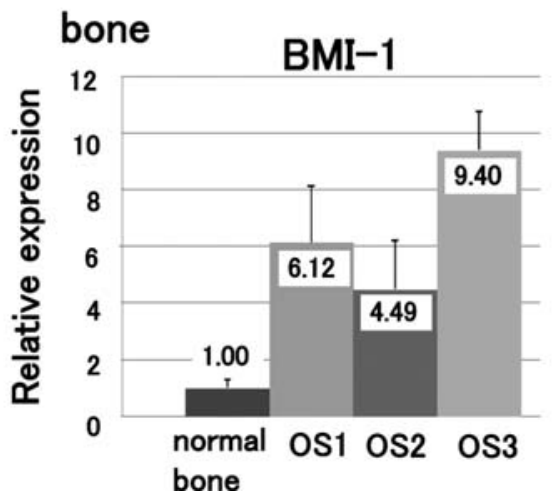

Figure 1. Overexpression of EZH2 and BMI-1 in osteosarcoma. (A) RT-PCR revealed that 3 osteosarcoma cell lines including NOS-1, 143B and HOS expressed EZH2 more strongly than NHOst (normal osteoblasts). (B) Real-time PCR revealed that expression of EZH2 in $143 B$, HOS, NOS-1 and Saos2 was increased 13-, 11-, 4.9- and 4.4-fold, respectively. (C) RT-PCR revealed that 3 osteosarcoma cell lines including NOS-1, 143B and HOS expressed BMI-1 more strongly than NHOst. (D) Real-time PCR revealed that expression of BMI-1 in 143B, HOS and NOS-1 was increased 6.7-, 3.7- and 3.7-fold, respectively, while that in Saos2 did not change appreciably. (E) Total RNA extracted from osteosarcoma biopsy samples were used for RT-PCR. RT-PCR revealed that osteosarcoma biopsy sample 1 (OS1), OS2 and OS3 expressed EZH2 more strongly than normal bone. (F) Real-time PCR revealed that expression of $E Z H 2$ in patient samples was increased 1.2- to 4.2-fold. (G) RT-PCR revealed that 3 osteosarcoma samples expressed $B M I-1$ more strongly than normal bone. (H) Real-time PCR revealed that expression of BMI-1 in patient samples increased 4.5- to 9.4-fold.

Knock-down of overexpressed EZH2 and BMI-1 does not prevent osteosarcoma growth in vitro or in vivo. It has been reported that overexpression of EZH2 or BMI-1 promotes malignant transformation $(21,36,38,40-47)$. In addition, inhibition of EZH2 or BMI-1 inhibits growth of various types of malignancies $(38,41,43,45,46)$. To determine whether knock-down of EZH2 and BMI-1 prevents osteosarcoma growth, we examined the effects of EZH2 and BMI-1 shRNA. We used 143B and HOS, which strongly express EZH2 and BMI-1. Real-time PCR revealed that shRNA effectively knocked-down EZH2 and BMI-1 (Fig. 3A). 143B and HOS were transfected with EZH2 shRNA, BMI-I shRNA and EZH2 shRNA plus BMI-1 shRNA. Unexpectedly, MTT assay revealed that the knock-down of EZH2, BMI-I and $E Z H 2$ plus $B M I-1$ did not prevent osteosarcoma growth in vitro (Fig. 3B-D). To confirm the effects of EZH2 and $B M I-1$ knock-down, we examined xenograft models. Nude mice were inoculated with control shRNA-transfected 143B cells, EZH2 shRNA-transfected 143B cells and BMI-1shRNA-transfected cells intradermally and tumor sizes were measured. Tumor sizes did not significantly differ among these three groups (Fig. 4).

\section{Discussion}

The PcG genes encode a family of evolutionarily conserved regulators that were discovered in Drosophila as repressors of homoeotic genes, which are involved in establishing body segmentation patterns during development. In mammalian systems, PcG proteins regulate genes involved in development 


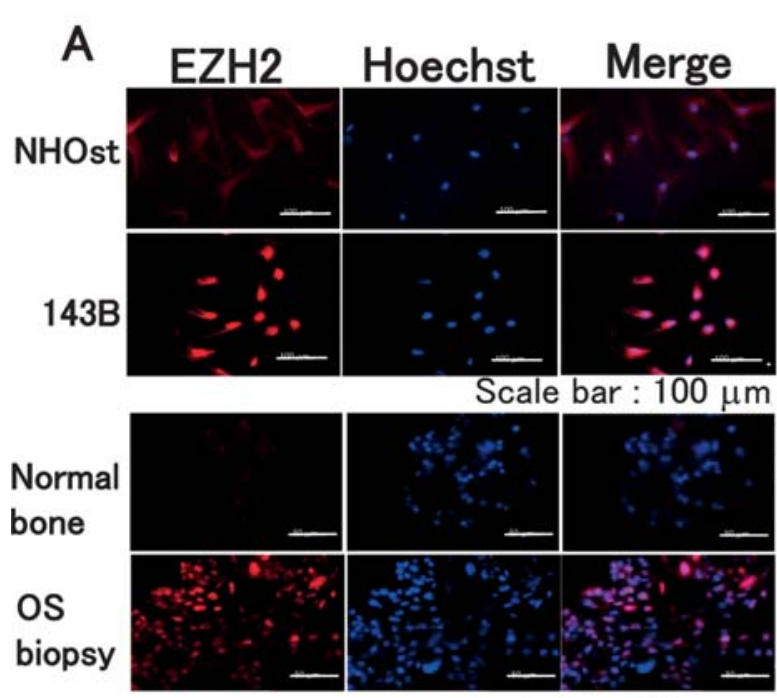

B

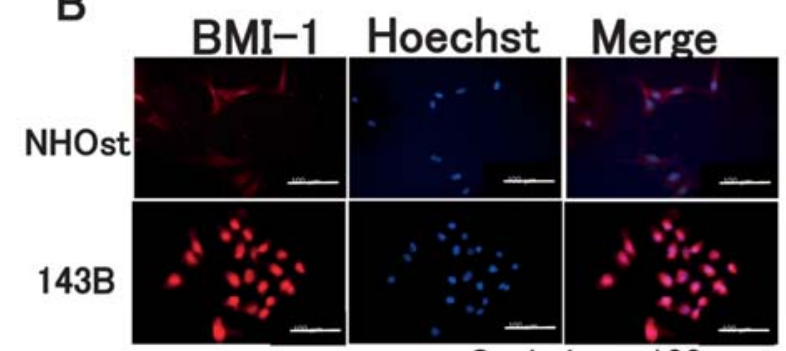

Scale bar : $100 \mu \mathrm{m}$

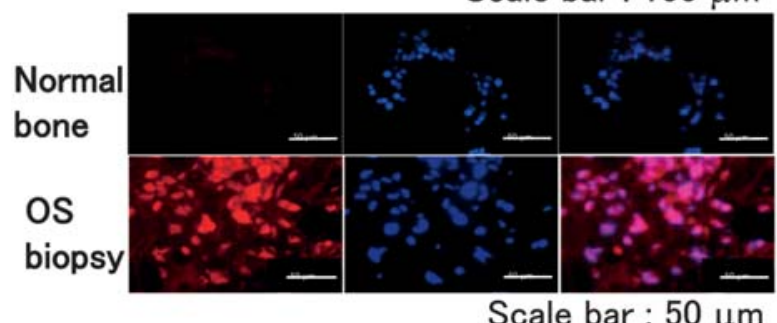

Scale bar : $50 \mu \mathrm{m}$

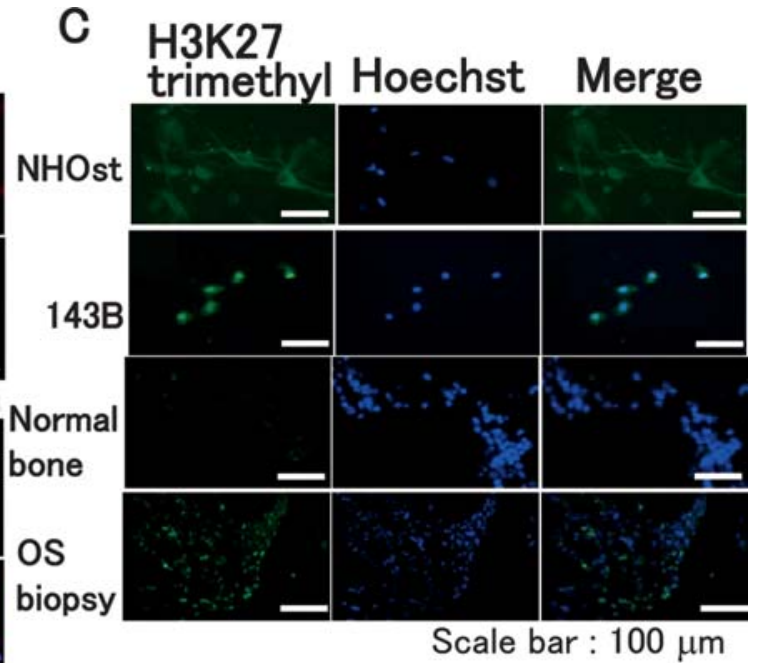

Figure 2. Histone H3-K27 is trimethylated in osteosarcoma which overexpressed EZH2 and BMI-1. (A) Immunohistochemical examination revealed that osteosarcoma cells lines and osteosarcoma biopsy samples expressed EZH2 more strongly than NHOst and normal bone tissue (red, EZH2; blue, Hoechst 33258). (B) Immunohistochemical examination revealed that osteosarcoma cells lines and osteosarcoma biopsy samples expressed BMI-1 more strongly than NHOst and normal bone tissue (red, BMI-1; blue, Hoechst 33258). (C) To determine if overexpression of polycomb proteins promoted histone H3K27 trimethylation, we performed immunohistochemistry using trimethylated histone H3K27-specific antibody. Histone H3K27 was found to be trimethylated more strongly in osteosarcoma cells lines and osteosarcoma biopsy samples than in normal osteoblasts and bone tissue (green, trimethylated histon H3K27; blue, Hoechst 33258). and differentiation via epigenetic mechanisms. Transcriptional profiling of human tumor samples holds significant promise for the advancement of cancer therapy, both in terms of improving diagnosis as well as predicting patient responses to treatment. Recently, an RNA expression signature associated with 'stem-cell-ness', based partly on PcGs-driven transcriptional changes, was postulated to predict poor therapeutic outcome in patients with various types of cancers (48). Although these claims await further validation, they suggest that levels of PcGs expression might prove valuable as prognostic markers, particularly because EZH2 and BMI-I overexpression appears to be tightly correlated with poor prognosis in various types of cancers $(49,50)$. BMI- 1 was originally identified as an oncogene (8). $B M I-1$ up-regulation induces development of B- and T-cell lymphomas $(7,41,42)$. In this study, we found that EZH2 and BMI- 1 RNAs are up-regulated in osteosarcoma cell lines and patient samples, following the study of overexpression of EZH2 in the U2OS human osteosarcoma cell line (51). Steele et al reported that $\mathrm{CD}^{+} \mathrm{T}$-cell epitopes derived from EZH2 and BMI-1 elicited $\mathrm{T}$-cell responses as assessed by IFN- $\gamma$ release confirming the presence of CD8 responses against these proteins in patients with cancer (52). These findings suggest that EZH2 and BMI-1 may be useful targets for cancer immunotherapy of osteosarcoma.

The PRC2 containing EZH2 controls gene repression through recruitment of histone deacetylase. This recruitment leads to local chromatin deacetylation and subsequent trimethylation of $\mathrm{Lys}_{27}$ of histone H3 (H3K27). Histone H3K27 trimethylation is a property of stably silenced heterochromatin. The PRC1 complex containing BMI-1 subsequently binds to histone H3K27, suppresses gene expression and contributes to the maintenance of epigenetic memory (53). In this study, we found that histone H3K27 was trimethylated both in osteosarcoma cell lines and patient samples. These findings suggest the possibility that overexpressed EZH2 and BMI-1 are functionally active and promote histone H3K27 trimethylation in osteosarcoma as in stem cells and other types of cancer cells $(45,54,55)$. In addition, trimethylated histone H3K27 suppresses target gene expression via epigenetic regulation $(45,55,56)$. The gene suppression may contribute to the pathogenesis of osteosarcoma. BMI-1 represses the transcription of cell cycle repressors encoded by the ink4a locus (41,57-59). Although PcG proteins are generally 

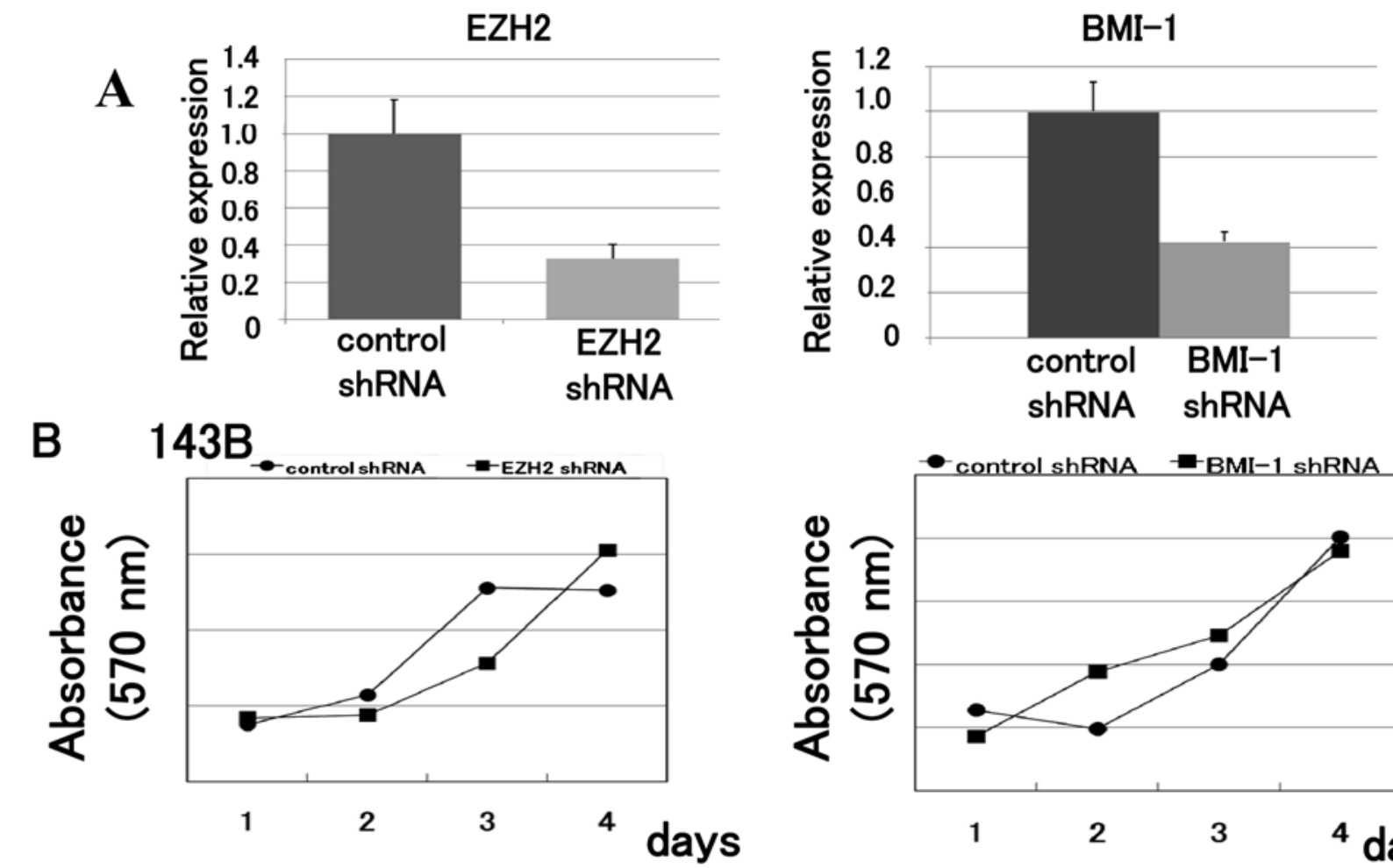

C HOS $\leftarrow$ control $\rightarrow$ EZH2 shRNA
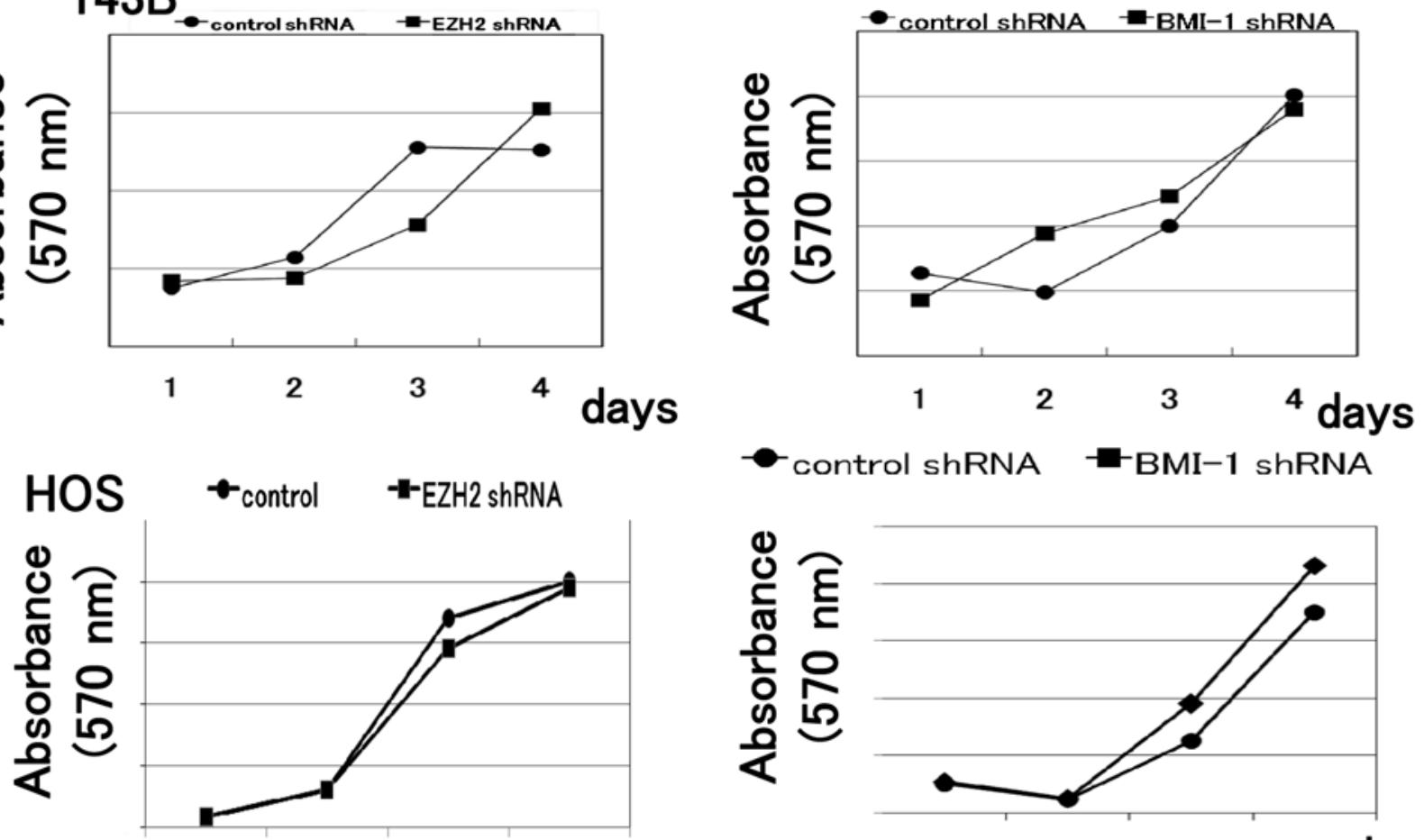

control shRNA $\quad-$ BMI-1 shRNA

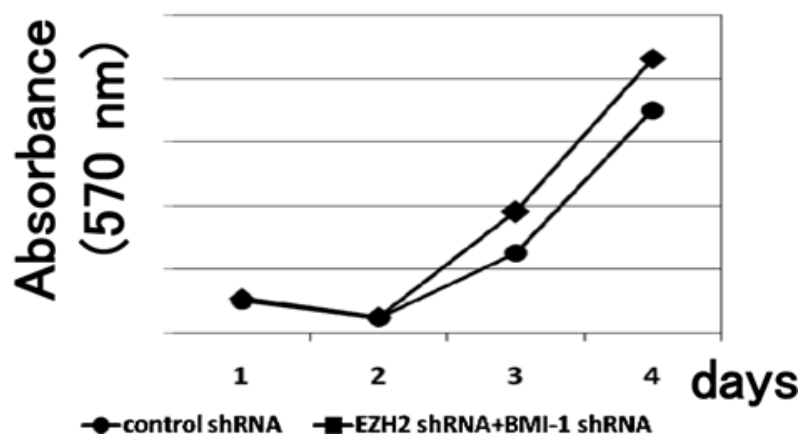

D HOS

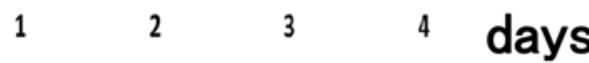

$\rightarrow-$ control shRNA

143B
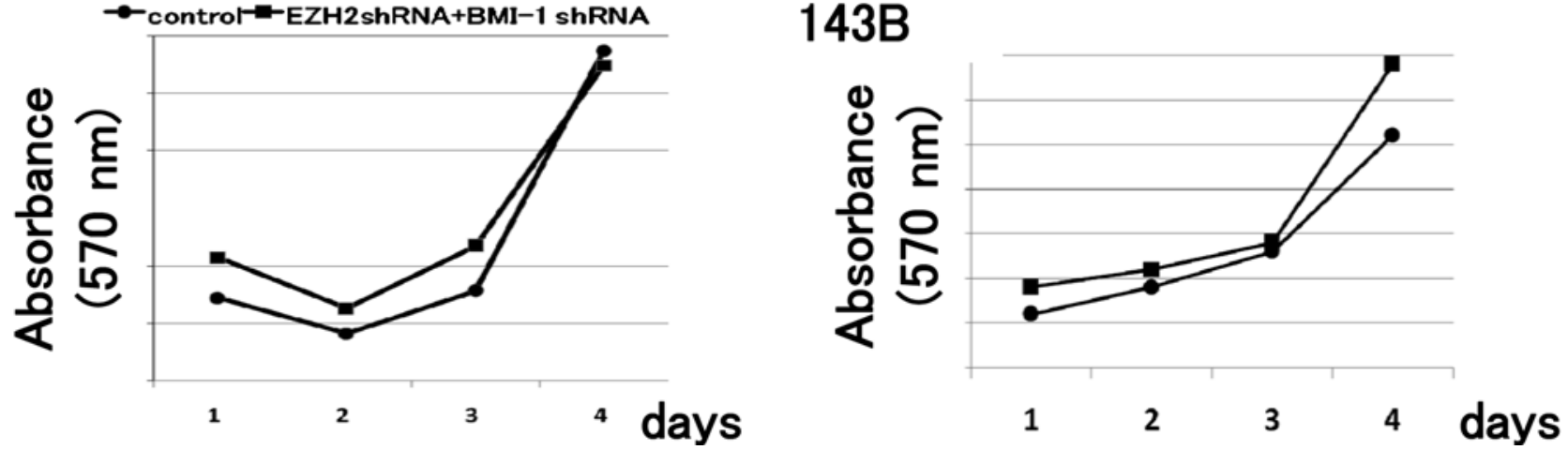

Figure 3. the knock-down of EZH2 and BMI-1 does not inhibit osteosarcoma growth in vitro. (A) 143B cells were transfected with EZH2 shRNA and BMI-1 shRNA. Real-time PCR revealed the knock-down effect by EZH2 shRNA or BMI-1 shRNA. (B) MTT assay showed that knock down of EZH2 and BMI-1 did not prevent 143B growth in vitro. (C) MTT assay showed that knock down of EZH2 and BMI-1 did not prevent HOS growth in vitro. (D) Double knock-down of EZH2 plus BMI-1 did not prevent HOS and 143B growth in vitro.

recognized as suppressors of target gene transcription, Shi et al reported that EZH2 enhances the transcription of c-myc and cyclin D1 (60). We previously found that transcription of c-myc is activated and expression of the ink4a locus are suppressed in osteosarcoma (61). These findings suggest that these genes may be targets of EZH2 and BMI- 1 in osteosarcoma.
It has been reported that overexpression of $E Z H 2$ or $B M I-1$ promotes malignant transformation $(21,36,38,40-47,49)$. In addition, inhibition of $E Z H 2$ or $B M I-1$ inhibits growth of various types of malignancies $(38,41-43,45,46,49)$. These findings suggest that $E Z H 2$ and $B M I-1$ play roles in regulating cell proliferation and survival and that $E Z H 2$ or $B M I-1$ may be useful as molecular targets in various types of malignancies. 

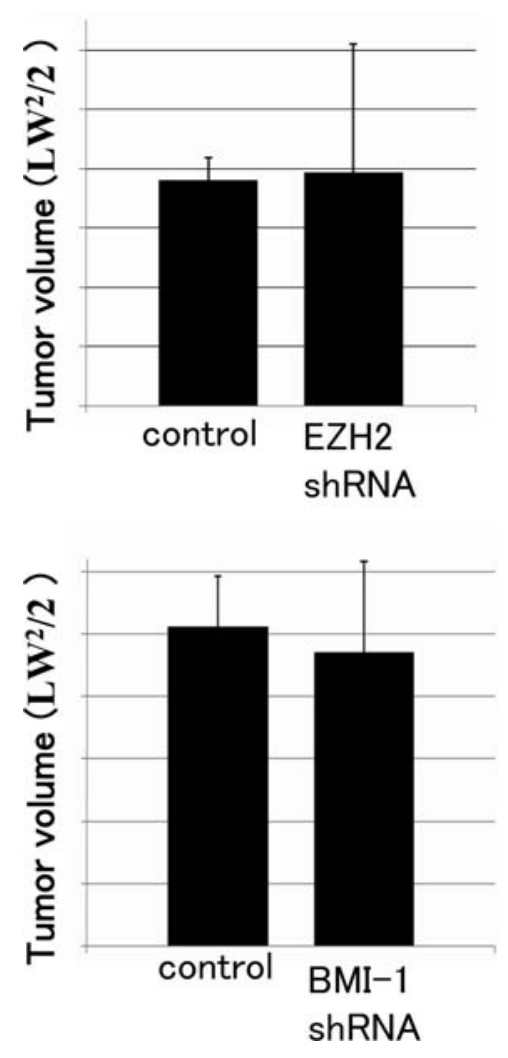

Figure 4. The knock-down of EZH2 and BMI-1 does not inhibit osteosarcoma growth in vivo. (A) Control shRNA-transfected 143B cells, EZH2-shRNA-transfected $143 \mathrm{~B}$ cells and BMI-1-shRNA-transfected cells $\left(1 \times 10^{5}\right)$ were inoculated subcutaneously. Established 143B tumors were measured. The tumor volume was evaluated 5 weeks after transplantation $(\mathrm{n}=3$, each group. Error bar, mean standard division).

In fact, pharmacologic interference of EZH2 function induces selective apoptosis of cancer cells but not normal cells (62). In the present study, we examined the effect of $E Z H 2$ and $B M I-1$ knock-down in osteosarcoma and found unexpectedly that $E Z H 2$ or BMI-1 knock-down by shRNA did not prevent osteosarcoma growth in vitro or in vivo. These findings are contrary to those reported in previous studies. Two groups reported that although $\mathrm{PcG}$ protein overexpression appeared to be correlated with poor prognosis for some types of malignancies, low BMI-1 expression was correlated with poor prognosis of endometrial carcinomas and malignant melanocytic lesion $(63,64)$. These studies suggest that osteosarcoma may be included among these types of malignancies. In addition, McGarvey et al reported that EZH2 knock-down results in increased expression of unmethylated and basally expressing genes but not of completely silenced and hypermethylated tumor suppressor genes (65). These findings suggest that important regulator genes for osteosarcoma growth may be hypermethylated. BMI-1 co-overexpression with other inducers, such as $H$-RAS, hTERT and $p 16^{I N K 4 a}$ shRNA, resulted in efficient malignant transformation $(36,40,41,44)$. These findings in turn suggest that other factors might be regulated in addition to BMI-1 to suppress osteosarcoma growth. Taken together, these findings suggest that inhibition of PcG proteins may not be useful for treatment of some other malignancies in addition to osteosarcoma.
In conclusion, we found that $E Z H 2$ and $B M I-1$ are upregulated in osteosarcoma. EZH2 and BMI-1 may be useful targets for cancer immunotherapy of osteosarcoma, although knock-down of EZH2 and BMI-1 could not prevent osteosarcoma growth. Further investigation of the functions of EZH2 and BMI-1 in osteosarcoma is needed.

\section{Acknowledgements}

This study was supported by Grants-in-Aid for Scientific Research (B) 18390419, (C) 19591725, Grant of Japan Orthopaedics and Traumatology Foundation, Inc. No. 0099 and No. 0145 and the Nakatomi Foundation.

\section{References}

1. Gibbs CP Jr, Weber K and Scarborough MT: Malignant bone tumors. Instr Course Lect 51: 413-428, 2002.

2. Satijn DP and Otte AP: Polycomb group protein complexes: do different complexes regulate distinct target genes? Biochim Biophys Acta 1447: 1-16, 1999.

3. Otte AP and Kwaks TH: Gene repression by Polycomb group protein complexes: a distinct complex for every occasion? Curr Opin Genet Dev 13: 448-454, 2003.

4. Satijn DP, Gunster MJ, van der Vlag J, et al: RING1 is associated with the polycomb group protein complex and acts as a transcriptional repressor. Mol Cell Biol 17: 4105-4113, 1997.

5. Schoorlemmer J, Marcos-Gutierrez C, Were F, et al: Ring1A is a transcriptional repressor that interacts with the Polycomb-M33 protein and is expressed at rhombomere boundaries in the mouse hindbrain. EMBO J 16: 5930-5942, 1997.

6. Gunster MJ, Satijn DP, Hamer KM, et al: Identification and characterization of interactions between the vertebrate polycombgroup protein BMI1 and human homologs of polyhomeotic. Mol Cell Biol 17: 2326-2335, 1997.

7. Alkema MJ, Bronk M, Verhoeven E, Otte A, van't Veer LJ, Berns A and van Lohuizen M: Identification of Bmi1-interacting proteins as constituents of a multimeric mammalian polycomb complex. Genes Dev 11: 226-240, 1997.

8. van Lohuizen M, Tijms M, Voncken JW, Schumacher A, Magnuson $\mathrm{T}$ and Wientjens E: Interaction of mouse polycomb-group $(\mathrm{Pc}-\mathrm{G})$ proteins Enx1 and Enx2 with Eed: indication for separate Pc-G complexes. Mol Cell Biol 18: 3572-3579, 1998.

9. Hashimoto N, Brock HW, Nomura M, et al: RAE28, BMI1, and M33 are members of heterogeneous multimeric mammalian Polycomb group complexes. Biochem Biophys Res Commun 245: 356-365, 1998.

10. Satijn DP and Otte AP: RING1 interacts with multiple Polycomb-group proteins and displays tumorigenic activity. Mol Cell Biol 19: 57-68, 1999.

11. Bardos JI, Saurin AJ, Tissot C, Duprez E and Freemont PS: HPC3 is a new human polycomb orthologue that interacts and associates with RING1 and Bmi1 and has transcriptional repression properties. J Biol Chem 275: 28785-28792, 2000.

12. Ng J, Hart CM, Morgan K and Simon JA: A Drosophila ESC$\mathrm{E}(\mathrm{Z})$ protein complex is distinct from other polycomb group complexes and contains covalently modified ESC. Mol Cell Biol 20: 3069-3078, 2000.

13. Satijn DP, Hamer KM, den Blaauwen J and Otte AP: The polycomb group protein EED interacts with YY1, and both proteins induce neural tissue in Xenopus embryos. Mol Cell Biol 21: $1360-1369,2001$

14. Tie F, Furuyama T, Prasad-Sinha J, Jane E and Harte PJ: The Drosophila Polycomb Group proteins ESC and E(Z) are present in a complex containing the histone-binding protein p55 and the histone deacetylase RPD3. Development 128: 275-286, 2001.

15. Furuyama T, Tie F and Harte PJ: Polycomb group proteins ESC and $E(Z)$ are present in multiple distinct complexes that undergo dynamic changes during development. Genesis 35: 114-124, 2003.

16. Cao R, Wang L, Wang H, et al: Role of histone H3 lysine 27 methylation in Polycomb-group silencing. Science 298: 1039-1043, 2002. 
17. Czermin B, Melfi R, McCabe D, Seitz V, Imhof A and Pirrotta V: Drosophila enhancer of Zeste/ESC complexes have a histone H3 methyltransferase activity that marks chromosomal Polycomb sites. Cell 111: 185-196, 2002.

18. Kuzmichev A, Nishioka K, Erdjument-Bromage H, Tempst $P$ and Reinberg D: Histone methyltransferase activity associated with a human multiprotein complex containing the Enhancer of Zeste protein. Genes Dev 16: 2893-2905, 2002.

19. Muller J, Hart CM, Francis NJ, et al: Histone methyltransferase activity of a Drosophila Polycomb group repressor complex. Cell 111: 197-208, 2002

20. Glinsky GV: Genomic models of metastatic cancer: functional analysis of death-from-cancer signature genes reveals aneuploid, anoikis-resistant, metastasis-enabling phenotype with altered cell cycle control and activated Polycomb Group (PcG) protein chromatin silencing pathway. Cell Cycle 5: 1208-1216, 2006.

21. Kleer CG, Cao Q, Varambally S, et al: EZH2 is a marker of aggressive breast cancer and promotes neoplastic transformation of breast epithelial cells. Proc Natl Acad Sci USA 100: 11606-11611, 2003

22. Raaphorst FM, Meijer CJ, Fieret E, et al: Poorly differentiated breast carcinoma is associated with increased expression of the human polycomb group EZH2 gene. Neoplasia 5: 481-488, 2003.

23. Breuer RH, Snijders PJ, Smit EF, et al: Increased expression of the EZH2 polycomb group gene in BMI-1-positive neoplastic cells during bronchial carcinogenesis. Neoplasia 6: 736-743, 2004.

24. Sudo T, Utsunomiya T, Mimori K, et al: Clinicopathological significance of EZH2 mRNA expression in patients with hepatocellular carcinoma. Br J Cancer 92: 1754-1758, 2005.

25. Weikert S, Christoph F, Kollermann J, Muller M, Schrader M, Miller K and Krause H: Expression levels of the EZH2 polycomb transcriptional repressor correlate with aggressiveness and invasive potential of bladder carcinomas. Int J Mol Med 16: 349-353, 2005

26. Mimori K, Ogawa K, Okamoto M, Sudo T, Inoue H and Mori M Clinical significance of enhancer of zeste homolog 2 expression in colorectal cancer cases. Eur J Surg Oncol 31 : 376-380, 2005

27. van Kemenade FJ, Raaphorst FM, Blokzijl T, et al: Coexpression of BMI-1 and EZH2 polycomb-group proteins is associated with cycling cells and degree of malignancy in B-cell non-Hodgkin lymphoma. Blood 97: 3896-3901, 2001.

28. Visser HP, Gunster MJ, Kluin-Nelemans HC, et al: The Polycomb group protein EZH2 is upregulated in proliferating, cultured human mantle cell lymphoma. Br J Haematol 112: 950-958, 2001.

29. Dukers DF, van Galen JC, Giroth C, et al: Unique polycomb gene expression pattern in Hodgkin's lymphoma and Hodgkin's lymphoma-derived cell lines. Am J Pathol 164: 873-881, 2004.

30. Raaphorst FM, van Kemenade FJ, Blokzijl T, et al: Coexpression of BMI-1 and EZH2 polycomb group genes in Reed-Sternberg cells of Hodgkin's disease. Am J Pathol 157: 709-715, 2000

31. Bea S, Tort F, Pinyol M, et al: BMI-1 gene amplification and overexpression in hematological malignancies occur mainly in mantle cell lymphomas. Cancer Res 61: 2409-2412, 2001.

32. Vonlanthen S, Heighway J, Altermatt HJ, et al: The bmi-1 oncoprotein is differentially expressed in non-small cell lung cancer and correlates with INK4A-ARF locus expression. Br J Cancer 84: 1372-1376, 2001.

33. Kim JH, Yoon SY, Kim CN, et al: The Bmi-1 oncoprotein is overexpressed in human colorectal cancer and correlates with the reduced p16INK4a/p14ARF proteins. Cancer Lett 203 : 217-224, 2004

34. Mihara K, Chowdhury M, Nakaju N, et al: Bmi-1 is useful as a novel molecular marker for predicting progression of myelodysplastic syndrome and patient prognosis. Blood 107: 305-308, 2006

35. Song LB, Zeng MS, Liao WT, et al: Bmi-1 is a novel molecular marker of nasopharyngeal carcinoma progression and immortalizes primary human nasopharyngeal epithelial cells. Cancer Res 66: 6225-6232, 2006.

36. Datta S, Hoenerhoff MJ, Bommi P, et al: Bmi-1 cooperates with $\mathrm{H}-\mathrm{R}$ as to transform human mammary epithelial cells via dysregulation of multiple growth-regulatory pathways. Cancer Res 67: 10286-10295, 2007.
37. Yang J, Chai L, Liu F, et al: Bmi-1 is a target gene for SALL4 in hematopoietic and leukemic cells. Proc Natl Acad Sci USA 104: 10494-10499, 2007.

38. Wiederschain D, Chen L, Johnson B, et al: Contribution of polycomb homologues Bmi-1 and Mel-18 to medulloblastoma pathogenesis. Mol Cell Biol 27: 4968-4979, 2007.

39. Hotta T, Motoyama T and Watanabe H: Three human osteosarcoma cell lines exhibiting different phenotypic expressions. Acta Pathol Jpn 42: 595-603, 1992.

40. Haga K, Ohno S, Yugawa T, et al: Efficient immortalization of primary human cells by p16INK4a-specific short hairpin RNA or Bmi-1, combined with introduction of hTERT. Cancer Sci 98: 147-154, 2007

41. Jacobs JJ, Kieboom K, Marino S, DePinho RA and van Lohuizen M: The oncogene and Polycomb-group gene bmi-1 regulates cell proliferation and senescence through the ink4a locus. Nature 397: 164-168, 1999.

42. Jacobs JJ, Scheijen B, Voncken JW, Kieboom K, Berns A and van Lohuizen M: Bmi-1 collaborates with c-Myc in tumorigenesis by inhibiting c-Myc-induced apoptosis via INK4a/ARF. Genes Dev 13: 2678-2690, 1999

43. Lessard J and Sauvageau G: Bmi-1 determines the proliferative capacity of normal and leukaemic stem cells. Nature 423: 255-260, 2003

44. Saito M, Handa K, Kiyono T, et al: Immortalization of cementoblast progenitor cells with Bmi-1 and TERT. J Bone Miner Res 20: 50-57, 2005.

45. Tonini T, D'Andrilli G, Fucito A, Gaspa L and Bagella L: Importance of Ezh2 polycomb protein in tumorigenesis process interfering with the pathway of growth suppressive key elements. J Cell Physiol 214: 295-300, 2008.

46. Varambally S, Dhanasekaran SM, Zhou M, et al: The polycomb group protein EZH2 is involved in progression of prostate cancer. Nature 419: 624-629, 2002.

47. Sellers WR and Loda M: The EZH2 polycomb transcriptional repressor - a marker or mover of metastatic prostate cancer? Cancer Cell 2: 349-350, 2002.

48. Glinsky GV, Berezovska O and Glinskii AB: Microarray analysis identifies a death-from-cancer signature predicting therapy failure in patients with multiple types of cancer. J Clin Invest 115: 1503-1521, 2005

49. Bracken AP, Pasini D, Capra M, Prosperini E, Colli E and Helin K: EZH2 is downstream of the pRB-E2F pathway, essential for proliferation and amplified in cancer. EMBO J 22: 5323-5335, 2003.

50. Kanno R, Janakiraman H and Kanno M: Epigenetic regulator polycomb group protein complexes control cell fate and cancer. Cancer Sci 99: 1077-1084, 2008.

51. Vire E, Brenner C, Deplus R, et al: The Polycomb group protein EZH2 directly controls DNA methylation. Nature 439: 871-874, 2006.

52. Steele JC, Torr EE, Noakes KL, et al: The polycomb group proteins, BMI-1 and EZH2, are tumour-associated antigens. Br J Cancer 95: 1202-1211, 2006

53. Fischle W, Wang Y, Jacobs SA, Kim Y, Allis CD and Khorasanizadeh S: Molecular basis for the discrimination of repressive methyl-lysine marks in histone $\mathrm{H} 3$ by Polycomb and HP1 chromodomains. Genes Dev 17: 1870-1881, 2003.

54. Schlesinger Y, Straussman R, Keshet I, et al: Polycombmediated methylation on Lys 27 of histone $\mathrm{H} 3$ pre-marks genes for de novo methylation in cancer. Nat Genet 39: 232-236, 2007.

55. Cao R and Zhang $\mathrm{Y}$ : The functions of $\mathrm{E}(\mathrm{Z}) / \mathrm{EZH} 2$-mediated methylation of lysine 27 in histone H3. Curr Opin Genet Dev 14: 155-164, 2004

56. Kondo Y, Shen L, Cheng AS, et al: Gene silencing in cancer by histone $\mathrm{H} 3$ lysine 27 trimethylation independent of promoter DNA methylation. Nat Genet 40: 741-750, 2008.

57. Silva J, Garcia JM, Pena C, et al: Implication of polycomb members Bmi-1, Mel-18, and Hpc-2 in the regulation of p16INK4a, p14ARF, h-TERT, and c-Myc expression in primary breast carcinomas. Clin Cancer Res 12: 6929-6936, 2006.

58. Pardal R, Molofsky AV, He S and Morrison SJ: Stem cell selfrenewal and cancer cell proliferation are regulated by common networks that balance the activation of proto-oncogenes and tumor suppressors. Cold Spring Harb Symp Quant Biol 70: 177-185, 2005.

59. Gil J and Peters G: Regulation of the INK4b-ARF-INK4a tumour suppressor locus: all for one or one for all. Nat Rev Mol Cell Biol 7: 667-677, 2006. 
60. Shi B, Liang J, Yang X, et al: Integration of estrogen and Wnt signaling circuits by the polycomb group protein EZH2 in breast cancer cells. Mol Cell Biol 27: 5105-5119, 2007.

61. Tanaka M, Setoguchi T, Hirotsu M, Gao H, Sasaki H, Matsunoshita Y and Komiya S: Inhibition of Notch pathway prevents osteosarcoma growth by cell cycle regulation. Br J Cancer 100: 1957-1965, 2009.

62. Tan J, Yang X, Zhuang L, et al: Pharmacologic disruption of Polycomb-repressive complex 2-mediated gene repression selectively induces apoptosis in cancer cells. Genes Dev 21: 1050-1063, 2007.
63. Engelsen IB, Mannelqvist M, Stefansson IM, et al: Low BMI-1 expression is associated with an activated BMI-1-driven signature, vascular invasion, and hormone receptor loss in endometrial carcinoma. Br J Cancer 98: 1662-1669, 2008.

64. Bachmann IM, Puntervoll HE, Otte AP and Akslen LA: Loss of BMI-1 expression is associated with clinical progress of malignant melanoma. Mod Pathol 21: 583-590, 2008.

65. McGarvey KM, Greene E, Fahrner JA, Jenuwein T and Baylin SB: DNA methylation and complete transcriptional silencing of cancer genes persist after depletion of EZH2. Cancer Res 67: 5097-5102, 2007. 